\title{
Retest Reliability of Prolactin Response to $d l$-Fenfluramine Challenge in Adults
}

\author{
Janine D. Flory, Ph.D., Stephen B. Manuck, Ph.D., and Matthew F. Muldoon, M.D., M.P.H.
}

\begin{abstract}
Neuropharmacologic probes to assess central nervous system (CNS) serotonergic responsivity (e.g., dl-fenfluramine) stimulate serotonergic neurotransmission, thereby causing proportional release of pituitary-derived hormones into the circulation. Individual differences in these hormonal responses are thus thought to reflect dimensional variability in central serotonergic activity, which may, in turn, underlie variation in serotonin-related traits of personality (e.g., impulsivity, behavioral inhibition, harm avoidance).

However, the long-term temporal stability of neuropharmacologic indices of CNS serotonergic responsivity has not previously been tested in nonpsychiatric patients. dl-Fenfluramine was administered here to 57 adults, aged 24-60 years, on two occasions 6 months apart,
\end{abstract}

to examine the retest reliability of fenfluramine-induced prolactin [PRL] response to fenfluramine. Baseline PRL concentration (i.e., before administration of fenfluramine) was highly stable over the 6 months $(r=0.88)$. Variability in serotonergic responsivity, adjusted for baseline PRL concentration, age, sex, and drug concentration during the challenge, was moderately reproducible ( $r=0.50$ for peak $\triangle P R L$ and 0.57 for PRL "area under the curve," $\mathrm{p}<$ .0001). These findings are consistent with speculation that variability in indices of central serotonergic function reflects a temporally stable dimension of individual differences.

[Neuropsychopharmacology 26:269-272, 2002] (C) 2002 American College of Neuropsychopharmacology. Published by Elsevier Science Inc.

\section{KEY WORDS: Serotonin, d,l-Fenfluramine, Retest reliability}

Although it is widely hypothesized that central nervous system (CNS) serotonergic function varies appreciably among individuals and that such variation may partially underlie differences in trait measures of disinhibition or impulsivity (e.g., Depue and Spoont, 1986; Soubrie 1986; Cloninger, 1987; Zuckerman, 1995), the retest reliability of interindividual variability in serotonergic function (and hence the temporal stability of this puta-

From the Behavioral Physiology Laboratory, Department of Psychology, University of Pittsburgh (JDF, SBM); and the Center for Clinical Pharmacology, University of Pittsburgh School of Medicine (MFM), Pittsburgh, PA

Address correspondence to: Janine D. Flory, Ph.D., Behavioral Physiology Laboratory, 506 OEH, 4015 O'Hara Street, University of Pittsburgh, Pittsburgh, PA 15260; E-mail: jdf3@pitt.edu.

Received February 7, 2001; revised June 14, 2001; accepted June 26, 2001.

Online publication: 7/6/01 at www.acnp.org/citations/Npp 070601145. tive neurobiologic dimension) remains unclear. Neuropharmacologic challenges are used to index serotonergic function, as reflected in the stimulated release of anterior pituitary hormones into the circulation (Murphy et al. 1990; Yatham and Steiner, 1993). The prolactin (PRL) response to fenfluramine hydrochloride has been used commonly to index central serotonergic responsivity in humans (Murphy et al. 1990). Fenfluramine has been favored over other agents because it potently induces presynaptic release of serotonin, blocks reuptake, and possibly activates postsynaptic receptors (Borroni et al. 1983; Quattrone et al. 1983; Coccaro et al., 1989), thereby providing a measure of net serotonergic responsivity.

With respect to retest reliability, Coccaro et al. (1987) reported that peak $\triangle \mathrm{PRL}$ response to fenfluramine was moderately correlated $(\mathrm{r}=0.75)$ in a sample of 13 male psychiatric patients over 2 to 12 days. Similarly, Stoff et al. (1992) demonstrated that the peak $\triangle$ PRL response to fenfluramine was reproducible $(\mathrm{r}=0.80)$ across 1 week 
among 10 boys with conduct disorder. Because these two studies examined patient samples (e.g., conduct disorder, major depression) in whom serotonergic function may be chronically dysregulated (e.g., Coccaro et al. 1989; Flory et al. 1998), it remains unclear to what extent normative variability in central serotonergic responsivity also reflects a reproducible dimension of individual differences.

The current study was conducted to examine the retest reliability of the PRL response to fenfluramine in 57 nonpsychiatric patients. Participants were derived from the untreated (placebo) condition of a 6-month clinical trial conducted to examine behavioral sequelae of a cholesterol-lowering medication (Muldoon et al. 2000). A fenfluramine challenge protocol was administered at the beginning and the end of the treatment period.

\section{METHOD}

\section{Participants}

Men and women, aged 24-60 years, were included in the clinical trial if their low density lipoprotein cholesterol (LDL-C) levels exceeded $160 \mathrm{mg} / \mathrm{dl}$. All participants were of good general health, and none were taking medications known to affect serotonergic responsivity or plasma prolactin concentrations, including psychotropic or glucocorticoid medications. Four participants were taking antihypertensive medications and six were using endogenous hormones (i.e., hormone replacement therapy or oral contraceptives) throughout the 6-month clinical trial. Medical exclusions from the clinical trial included cancer treatment within the past year, stroke, diabetes requiring pharmacological treatment, chronic kidney or liver disease, untreated hypertension, schizophrenia, or delusional disorder. Pregnant or lactating women were also excluded from participating in the study.

Fenfluramine challenge data were available on 57 individuals, including 26 women and 31 men with an average age of 46 years $(\mathrm{SEM}=1.0)$. Thirty-six percent of the participants had a baccalaureate or higher degree, and 90 percent of the sample was employed. Fifty-one participants were Caucasian, five were African American, and one was Asian American. Nine individuals (16\%) met criteria for a current DSM-III-R Axis I diagnosis of mild to moderate severity at one or both assessments based on structured clinical interview (Structured Clinical Interview for DSM-III-R: Non-Patient Edition [Spitzer et al., 1990]), but none were receiving treatment. Diagnoses included social phobia $(n=1)$, simple phobia $(n=1)$, alcohol dependence $(n=3)$, a nonpsychotic mood disorder $(n=3)$, and adjustment disorder $(n=1)$. All statistical analyses reported below retained significance on reanalysis excluding these nine individuals. Participants provided written, informed consent, and the protocol was approved by the Institutional Review Board at the University of Pittsburgh.

\section{Procedure}

Fenfluramine Challenge. The protocol for the challenge has been described in detail (Manuck et al. 1998). Briefly, participants reported to the laboratory in the morning after a 12-h fast. A 20-gauge, heparin-locked catheter was introduced aseptically into a vein in the antecubital fossa. After a 30-min adaptation period, a blood sample to determine baseline (i.e., pre-administration) plasma PRL concentration was drawn, after which $d l$-Fenfluramine hydrochloride was administered orally as a single dose of $30-60 \mathrm{mg}$ in $10-\mathrm{mg}$ increments to best approximate a weight relative administration of $0.55-0.65 \mathrm{mg}$ fenfluramine $/ \mathrm{kg}$ body weight. Blood samples were drawn 60, 120, 150, 180, and 210 min later. Plasma PRL concentration was determined from each sample, and fenfluramine and norfenfluramine concentrations during the challenge were determined from samples drawn at 150 and $210 \mathrm{~min}$. All blood samples were centrifuged, separated, and frozen at $-70^{\circ} \mathrm{C}$ until analysis. An identical protocol was repeated after 6 months (average days $=181 ; \mathrm{SEM}=2.7]$ ).

PRL Assay. Plasma PRL levels were determined in duplicate using Immunocorp's (Montreal, Canada) solid phase two-site immunoradiometric method. The lower limit of sensitivity of the PRL assay is $0.5 \mathrm{ng} / \mathrm{ml}$, and the interassay coefficient of variation is $6-9 \%$. The lower detection limit of the fenfluramine/norfenfluramine assays is $2.0 \mathrm{ng} / \mathrm{ml}$, and the coefficient of variation is $5.2 \%$ at $5.0 \mathrm{ng} / \mathrm{ml}$.

\section{Statistical Analyses}

Peak PRL response ( $\triangle \mathrm{PRL}[\mathrm{fen}])$ was expressed as the arithmetic difference between the highest PRL concentration obtained after drug administration and preadministration PRL concentration. The area under the response curve (AUC PRL[fen]) was calculated using trapezoidal integration. These two indices of serotonergic responsivity were then adjusted by regression for any covariation with pre-administration PRL concentration, sex, age, or fenfluramine and norfenfluramine concentrations during the challenge. The temporal stability of individual differences in these indices of serotonergic responsivity was examined with Pearson correlations, computed across the 6-month interval. Among women, the challenges were performed without control for menstrual cycle phase, and, because PRL response to fenfluramine is known to vary appreciably across the menstrual cycle (O'Keane et al. 1991), the correlations were repeated excluding premenopausal women and post- 
menopausal women taking hormone replacement therapy according to a cyclic schedule $(n=15)$.

\section{RESULTS AND DISCUSSION}

Baseline PRL levels, unadjusted $\triangle$ PRL[fen], and AUC PRL[fen] levels at both assessments are presented in Table 1, for men and women separately. Because of practical constraints, we shortened the standard 5-h protocol to $3.5 \mathrm{~h}$, which may account for adjusted $\triangle$ PRL[fen] values that are somewhat lower than previous reports (e.g., Coccaro et al. 1987; Stoff et al., 1992). As we have reported previously (Manuck et al., 1998), however, peak PRL concentrations during abbreviated and standard protocols correlated 0.91 in a separate sample of 42 individuals who completed the 5-h protocol, indicating high concordance for peak PRL concentrations across the two sampling intervals.

Retest correlations for baseline PRL levels and the two indices of serotonergic responsivity are presented in Table 2. Baseline, or preadministration, PRL levels were highly stable over 6 months, with a correlation of 0.88 across all participants. Adjusted $\Delta$ PRL[fen] concentrations and AUC PRL[fen] were moderately reproducible across time in the total sample $(r=0.50$ and 0.57 , respectively; $p<.0001$ ). When cycling women were excluded from the analyses, the retest correlations were comparable, increasing to $0.54(p<.0001)$ for adjusted $\Delta$ PRL[fen] and $0.59(p<.0001)$ for adjusted AUC PRL[fen]. These results demonstrate moderate retest reliability for the fenfluramine challenge when used as an index of CNS serotonergic responsivity in adults. That the results of the current study were not stronger may be due to the interval between measurements, which was considerably longer than that of previous reports, that is, 6 months compared with 1-2 weeks in the

Table 1. Sample Characteristics and Plasma Prolactin Levels (Mean \pm SEM.)

\begin{tabular}{|c|c|c|}
\hline & $\operatorname{Men}(n=31)$ & Women $(n=26)$ \\
\hline Age (years) & $45.5(1.2)$ & $46.2(1.7)$ \\
\hline Weight (kg) & $85.3(2.0)$ & $70.5(2.6)$ \\
\hline $\begin{array}{l}\text { Baseline PRL (ng/ml) } \\
\text { session } 1\end{array}$ & $6.5(0.4)$ & $8.0(1.0)$ \\
\hline $\begin{array}{l}\text { Baseline PRL }(\mathrm{ng} / \mathrm{ml}) \\
\text { session } 2\end{array}$ & $6.2(0.4)$ & $8.4(1.0)$ \\
\hline $\begin{array}{l}\Delta \mathrm{PRL}[\mathrm{fen}]^{a}(\mathrm{ng} / \mathrm{ml}) \\
\quad \text { session } 1\end{array}$ & $2.9(0.6)$ & $3.6(0.7)$ \\
\hline $\begin{array}{l}\Delta \mathrm{PRL}[\mathrm{fen}](\mathrm{ng} / \mathrm{ml}) \\
\quad \text { session } 2\end{array}$ & $2.9(0.5)$ & $4.0(1.0)$ \\
\hline $\begin{array}{l}\text { AUC PRL[fen] } \\
\text { ([ng/ml] }]^{a} \text { hr) session } 1 \\
\text { AUC PRL[fen] }\end{array}$ & $23.1(1.5)$ & $29.1(3.4)$ \\
\hline$\left([\mathrm{ng} / \mathrm{ml}]^{a} \mathrm{hr}\right)$ session 2 & $22.3(1.6)$ & $31.3(3.7)$ \\
\hline
\end{tabular}

${ }^{*} \Delta$ PRL[fen] and AUC PRL [fen] values are unadjusted. studies reported by Coccaro et al. (1987) and Stoff et al. (1992).

The results of the current study are consistent with previous reports showing good stability of the prolactin response to fenfluramine in psychiatric patients (Coccaro et al., 1987; Stoff et al., 1992). Participants in the current study were generally healthy, and none were receiving psychopharmacological treatment. However, all had elevated LDL-C concentrations. In the current sample, we are unable to evaluate hypotheses linking (low) serum cholesterol to psychiatric disorders and behaviors associated with dysregulated 5-HT responsivity (e.g., depression, impulsive aggression, suicide). It might be noted that within the restricted range of lipid concentrations present in our sample, neither the adjusted $\Delta P R L$ [fen] concentrations nor the AUC PRL[fen] were associated with variability in total cholesterol, LDL-C, or high density lipoprotein cholesterol levels at either occasion of testing $(\mathrm{r}=-0.18-0.14)$. Thus, to the extent that cholesterol varied in this sample, it was unrelated to measures of CNS serotonergic responsivity.

Hormonal responses to fenfluramine are thought to represent net CNS serotonergic responsivity, because fenfluramine both stimulates presynaptic release of serotonin and blocks reuptake. It is not clear, however, whether hormonal responses to agents that preferentially target pre- or postsynaptic events or specific serotonin receptors are temporally stable. For example, intravenous infusion of clomipramine, which blocks serotonin reuptake, was associated with comparable peak prolactin responses across 4 weeks in healthy men but not across 2 weeks in a separate group of healthy men (Gilmore et al., 1993). The reproducibility of hormonal responses to selective serotonin reuptake inhibitors awaits further confirmation.

To conclude, the findings of this study are consistent with speculation that interindividual variability on indices of serotonergic function reflects a stable neurobiologic dimension of individual differences that may in turn underlie variation in serotonin-associated traits of personality or temperament.

Table 2. Retest Reliability Correlation Coefficients for Prolactin Levels Across 6 Months

\begin{tabular}{lcc}
\hline & $\begin{array}{c}\text { All Subjects } \\
(\boldsymbol{n}=57)\end{array}$ & $\begin{array}{c}\text { Men and Noncycling Women } \\
(\boldsymbol{n}=\mathbf{4 2})\end{array}$ \\
\hline Baseline & $.88^{*}$ & $.84^{*}$ \\
$\Delta$ PRL[fen] & $.50^{*}$ & $.54^{*}$ \\
AUC PRL[fen] & $.57^{*}$ & $.59^{*}$ \\
\hline
\end{tabular}

${ }^{*} p<.0001$, two-tailed

$\triangle \mathrm{PRL}[\mathrm{fen}]$ and AUC PRL[fen] are adjusted for baseline prolactin concentration, age, sex, and fenfluramine/norfenfluramine drug levels during the challenge. 


\section{ACKNOWLEDGMENTS}

This research was supported by National Institutes of Health grant HL46328 (MFM).

\section{REFERENCES}

Borroni E, Ceci A, Garattini S, Mennini T (1983): Differences between d-fenfluramine and d-norfenfluramine in serotonin presynaptic mechanisms. J Neurochemistry 40:891-893

Cloninger CR (1987): A systematic method for clinical description and classification of personality variants. Arch Gen Psychiatry 44:573-588

Coccaro EF, Siever LJ, Klar H, Rubenstein K, Benjamin E, Davis KL (1987): Diminished prolactin responses to repeated fenfluramine challenge in man. Psychiatry Res 22:257-259

Coccaro EF, Siever LJ, Klar HM, Maurer G, Cochrane K, Cooper TB, Mohs RC, Davis KL (1989): Serotonergic studies in patients with affective and personality disorders: Correlates with suicidal and impulsive aggressive behavior. Arch Gen Psychiatry 46:587-599

Depue RA, Spoont MR (1986): Conceptualizing a serotonin trait: A behavioral dimension of constraint. Ann NY Acad Sci 487:47-62

Flory JD, Mann JJ, Manuck SB, Muldoon MF (1998): Recovery from major depression is not associated with normalization of serotonergic function. Biol Psychiatry 43:320-326

Gilmore JH, Ruegg RG, Ekstrom RD, Knight B, Carson SW, Mason GA, Golden RN (1993): Altered prolactin response to clompiramine rechallenge in healthy subjects. Biol Psychiatry 34:885-888

Manuck SB, Flory JD, McCaffery JM, Matthews KA, Mann JJ, Muldoon MF (1998): Aggression, impulsivity, and cen- tral nervous system serotonergic responsivity in a nonpatient sample. Neuropsychopharmacology 19:287-299

Muldoon MF, Barger SD, Ryan CM, Flory JD, Lehoczky JP, Matthews KA, Manuck SB (2000): Effects of lovastatin on cognitive function and psychological well-being. Am J Med 108:538-547

Murphy DL, Mellow AM, Sunderland T, Aulakh CS, Lawlor BL, Zohar J (1990): Strategies for the study of serotonin in humans. In Coccaro EF, Murphy DL (eds), Serotonin in Major Psychiatric Disorders. Washington, DC, American Psychiatric Press, pp 3-25.

O'Keane V, O'Hanlon M, Webb M, Dinan T (1991): d-Fenfluramine/prolactin response throughout the menstrual cycle: Evidence for an oestrogen-induced alteration. Clin Endocrinol 34:289-292

Quattrone A, Tedeschi G, Aguglia U, Scopacasa F, DiRenzo GF, Annunziato L (1983): Prolactin secretion in man, a useful tool to evaluate the activity of drugs on central 5-hydroxytryptaminergic neurons: Studies with fenfluramine. Br J Clin Pharmacol 16:471-475

Soubrie P (1986): Reconciling the role of central serotonin neurons in humans and animal behavior. Behav Brain Sci 9:319-364

Spitzer RL, Williams JBW, Gibbon M, First MB (1990): Structured Clinical Interview for DSM-III-R: Non-Patient Edition (SCID-NP Version 10). Washington, DC,: American Psychiatric Press.

Stoff DM, Pasatiempo AP, Yeung JH, Bridger WH, Rabinovich H (1992): Test-retest reliability of the prolactin and cortisol responses to d,l-fenfluramine challenge in disruptive behavior disorders. Psychiatry Res 42:65-72

Yatham LN, Steiner M (1993): Neuroendocrine probes of serotonergic function: A critical review. Life Sci 53:447463

Zuckerman M (1995): Good and bad humors: Biochemical bases of personality and its disorders. Psycholog Sci $6: 325-332$ 